\title{
An Ultra-Wideband Sensing Board for IoT
}

\author{
A. Petrocchi, A. Raffo, G. Avolio, K. Lukasik, D. Resca, G. Vannini, S. Lemey, O. Caytan, \\ S. Agneessens, H. Rogier, D. Schreurs
}

\begin{abstract}
In this paper, we present an ultra-wideband impedance sensing board for the radio-frequency front-ends used in wireless units for the Internet of Things and the fifthgeneration wireless communication systems. We adopt as an impedance sensing board a six-port junction which was designed, fabricated, and tested experimentally in the frequency range from $5 \mathrm{GHz}$ to $6 \mathrm{GHz}$. Moreover, the sensing board functionality was fully validated with load-pull measurements carried out in the same frequency range.
\end{abstract}

Keywords-Internet of Things, Load-pull measurements, RF front-ends, Six-port junction, Ultra-wideband.

\section{INTRODUCTION}

In the area of wireless communications and networking, the interest in devices for Internet of Things (IoT) [1] and for the fifth generation $(5 \mathrm{G})$ [2] wireless network applications has been growing a lot. The main goal is the communication of these objects with each other, allowing the exchange of information between the devices themselves and with the users. These new ultra-wideband (UWB) devices will be implemented in common objects and they will be deployed in adverse conditions that may cause significant variations in the performance of the transmitter (Fig. 1). Moreover, the antenna's near field might vary dynamically in real operating conditions affecting the antenna input impedance. The latter has the strongest impact at the radio-frequency (RF) front end side, whose performance is strongly sensitive to variations in the antenna's input impedance. These variations significantly affect the RF front end performance in terms of gain, linearity, and data-rate. Several approaches have been proposed in literature to maintain stable RF front end performances under varying antenna mismatch, including the use of isolators [3], or of a reconfigurable matching network between the power amplifier (PA) and the antenna [4], or of predistortion techniques to adapt the input signal to the PA to compensate the varying load mismatch [3].

A. Petrocchi, G. Avolio, K. Lukasik, D. Schreurs are with the Electronic Engineering Department, KU Leuven, Leuven, Belgium (e-mail: apetrocc@esat.kuleuven.be).

A. Petrocchi, A. Raffo, G. Vannini are with the Department of Engineering, University of Ferrara, Ferrara, Italy (e-mail: antonio.raffo@unife.it).

K.Lukasik is with the Faculty of Electronics and Information Technology, Warsaw University of Technology, Warsaw, Poland.

D. Resca is with Microwave Electronics for Communications (MEC) Srl, Bologna, Italy.

S. Lemey, O. Caytan, S. Agneessens, H. Rogier are with the Department of Information Technology, University of Ghent, Ghent, Belgium (e-mail: hendrik.rogier@ugent.be).
In this work, we focus on an ultra-wideband low-cost solution for the targeted application (IoT and 5G). The main aim is the design of an ultra-wideband sensing board able to detect the antenna input impedance variations. The latter will be used together with a dedicated antenna plus a reconfigurable matching network which will properly modify the value of the antenna's input impedance, to maintain good $\mathrm{RF}$ front end performance. Several solutions to sense the antenna impedance have already been proposed in literature. For example, in [5], [6] a directional coupler is combined with a quadrature down converter. These approaches, however, are not fully suited to the target application, being the IoT, in terms of energy consumption, as DC bias is needed.

In this paper, we adopted as sensing board a passive solution based on a six-port junction [7], [8]. The six-port concept is well-known in literature and it has already been demonstrated for a plethora of uses in microwave and wireless applications, including reflectometer and direct conversion receiver for communications. For the considered wireless applications, the six-port concept has been adopted because of the demand of simple and low-cost transceivers in IoT [9]. The design of the six-port junction is carried out for the 5 $\mathrm{GHz}-6 \mathrm{GHz}$ frequency range. Furthermore, we characterized it by means of load-pull measurements in order to mimic antenna input impedance variations.

This paper is organized as follows. In Section II, we discuss the design of the six-port junction, its characterization, and its calibration. In Section III, the performed load-pull measurements are presented with the corresponding results. Finally, we draw conclusions.

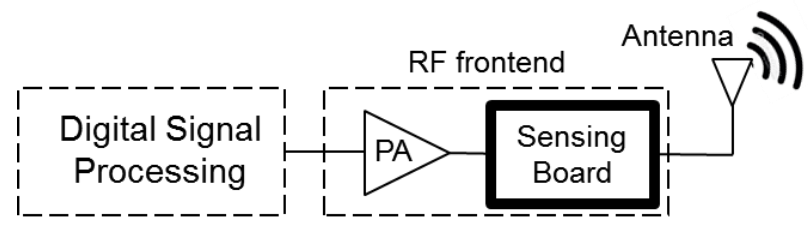

Fig. 1 Simplified block scheme of a transmitter affected by environmental changes on the antenna.

\section{DESIGN OF THE SENSING BOARD}

In this section, we present the main characteristics of the six-port junction.

\section{A. Six-Port Junction Design Specifications}

In this paragraph, the design of the six-port junction is presented. The latter is a simple, low-cost and accurate structure. It has two inputs and four outputs (see Fig. 2). Port 
one is connected to the output of the front end (i.e., power amplifier (PA) in Fig. 2) and port two to the antenna (i.e., Antenna in Fig. 2), while ports three, four, five and six (P3, P4, P5, P6 in Fig. 2) are connected to power sensors.

By reading the power at these four output ports, we obtain the value of the amplitude and phase of the antenna impedance [7], [8].

The six-port junction is designed to cover the frequency range from $(5 \mathrm{GHz}-6 \mathrm{GHz})$ which includes all unlicensed national information infrastructure (U- NII) radio bands, the 5 $\mathrm{GHz} \mathrm{Wi}-\mathrm{Fi}$ band, and it is suitable for 802.11ac Wi-Fi access points (APs).

The adopted structure of the six-port junction is shown in Fig. 2 and it is composed of a $12-\mathrm{dB}$ directional coupler, a Wilkinson power divider, three $90^{\circ}$ hybrid couplers, and a 3 $\mathrm{dB}$ attenuator. The choice of the coupling factor (CF) was made as a trade-off between fabrication cost and accuracy of the power measured at the four output ports. Indeed, by increasing the $\mathrm{CF}$, the six-port junction is more sensitive to errors and this will impact the reading of the unknown load $\Gamma$ [7], [8].

An initial design was done by using ideal transmission lines and considering $5.5 \mathrm{GHz}$ as the central frequency. After this step, we proceeded with the design by using microstrip lines manufactured on the R04350B low cost PCB substrate with dielectric constant of 3.48 and thickness of $0.508 \mathrm{~mm}$. The layout of the six port junction was drawn and optimized with Keysight ADS Momentum. A first prototype of the fabricated board is shown in Fig. 3 and dimensions are $68 \mathrm{~mm}$ x $76 \mathrm{~mm}$ which can be conveniently reduced adopting a different substrate (e.g., alumina) or optimizing the sensing board layout.

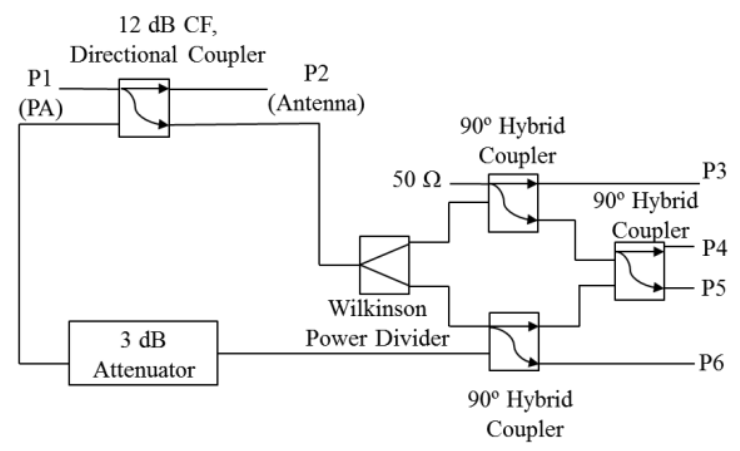

Fig. 2 Block scheme of six-port junction [8].

\section{B. Scattering-Parameter Measurements}

We measured the scattering (S-) parameters of our board between $4 \mathrm{GHz}$ and $7 \mathrm{GHz}$ with a Keysight PNA-X.

In particular, the measured S-parameters shown in Fig. 4 describe the paths between P3-P1 and P6-P1 (Fig. 4a) and between P5-P1 and P4-P1 (Fig. 4b). Note that these paths have to be equal [9] and in our case we satisfy this condition quite well, notably in the targeted frequency range (5 GHz-6 $\mathrm{GHz})$.

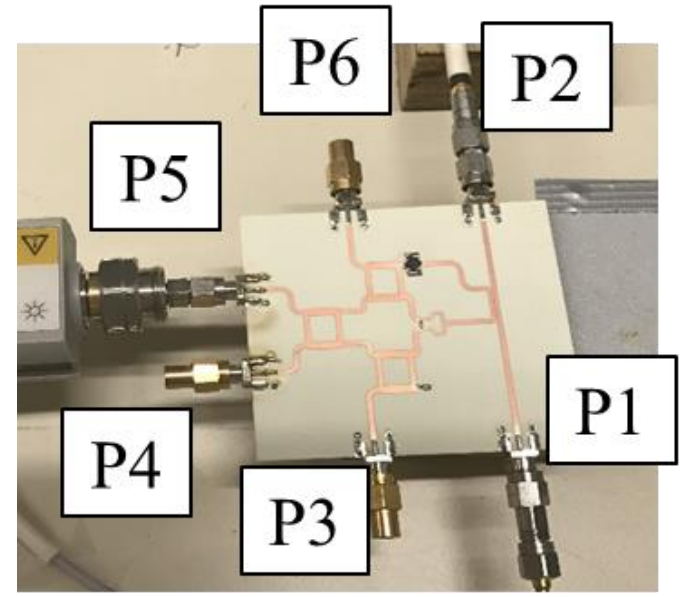

Fig. 3 Fabricated six-port junction board.

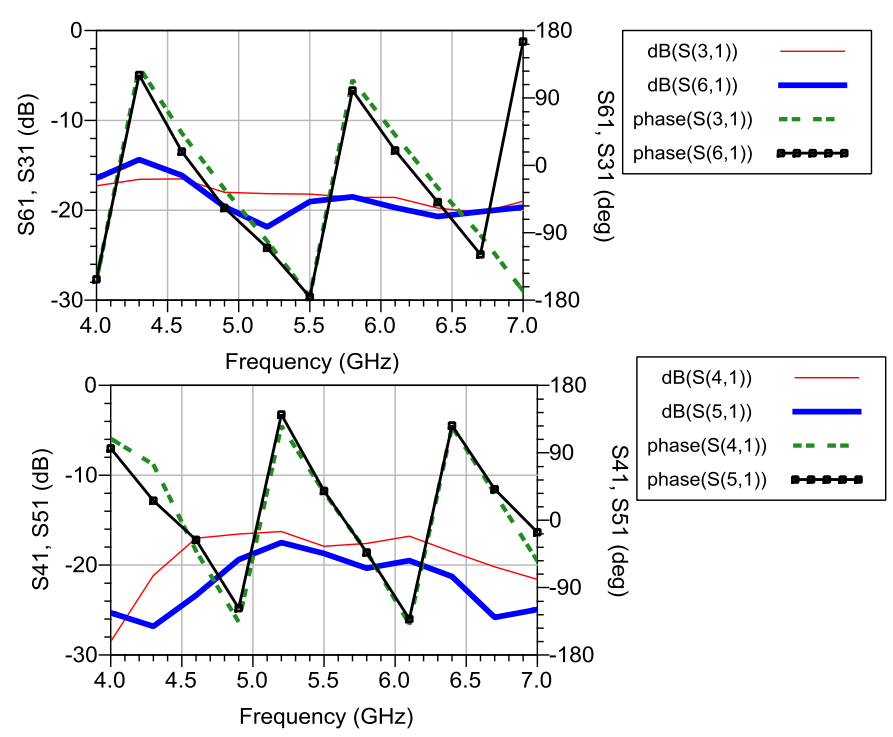

Fig. 4 Measurement results of the six-port junction: magnitude of S31 and S41 is reported with red solid line and the magnitude of S61 and S51 is reported with thick blue solid line. The phase of S31 and S41 is reported with green dotted line and the phase of S61 and S51 is shown with black squares line.

\section{Calibration Procedure}

In order to derive the unknown impedance from the power readings at P3-P6 (see Fig. 2), we calibrated the six-port junction with a linear algorithm that uses five calibration standards [10]. The main step in this algorithm is the calculation of the matrix $C$ which characterizes the six-port junction. The latter is a $(4 \times 4)$ real matrix which links the vector of the four read powers $(P)$ to the unknown load $(\Gamma)$ [10] by,

$$
\mathrm{P}=\rho \mathrm{C} \Gamma
$$

where $\rho=\left|b_{2}\right|^{2}$ is the incident wave at the antenna input port (i.e., Antenna in Fig. 2).

After connecting these five standards and after reading the associated power at the four output ports, it is possible to perform the calculations to get the unknown load. The chosen 
five loads for the calibration of the six-port junction are reported in Table I. These five standards are chosen taking into account the possible values of the antenna input impedance and considering also the conditional number of the matrix $C$ [11]. Indeed, we can link the accuracy of the calibration result and the choice of these five standards with the conditional number of the matrix $C$. For the loads reported in Table $\mathrm{I}$, the conditional number of the matrix $C$ is 5 .

The unknown load is deduced as written in (2) where the coefficients $x_{i j}$ are the entries of the matrix $X$ defined as the inverse matrix of $C$.

$$
\operatorname{Re}(\Gamma)=\frac{\sum_{j=1}^{4} x_{3 j} P_{j+2}}{\sum_{j=1}^{4} x_{1 j} P_{j+2}} \operatorname{Im}(\Gamma)=\frac{\sum_{j=1}^{4} x_{4 j} P_{j+2}}{\sum_{j=1}^{4} x_{1 j} P_{j+2}}
$$

TABLE I

CALIBRATION LOADS

\begin{tabular}{ll}
\hline \hline $\mathrm{Z}_{\mathrm{LOAD} 1}=40-\mathrm{j} 50 \Omega$ & $\mathrm{Z}_{\mathrm{LOAD} 2}=5-\mathrm{j} 15 \Omega$ \\
$\mathrm{Z}_{\mathrm{LOAD} 3}=0.82-\mathrm{j} 98.68 \Omega$ & $\mathrm{Z}_{\mathrm{LOAD} 4}=23-\mathrm{j} 51 \Omega$ \\
$\mathrm{Z}_{\mathrm{LOAD5}}=74+\mathrm{j} 55 \Omega$ & \\
\hline \hline
\end{tabular}

\section{LOAD PULl MEASUREMENTS}

We validated the designed six-port junction by performing load-pull measurements between $5 \mathrm{GHz}$ and $6 \mathrm{GHz}$. By connecting a passive tuner at the antenna port, we were able to mimic the real-world behaviour of the antenna impedance [9].

In particular, we used a set of impedances obtained by measuring a dedicated 5.15-5.85 GHz antenna array for high data-rate ultra-short-range $3 \times 3$ multiple input multiple output (MIMO) wireless communication [12]. Antenna impedance was measured in several configurations, e.g., in a free space and in a realistic office environment. For both cases, we had two configurations, one with the antenna array integrated in a worktop, and the other with the antenna array positioned in the quiet zone of the anechoic chamber. The measured antenna impedances are reported in Table II.

TABLE II

IMPEDANCES OF AN ANTENNA FOR MIMO WIRELESS COMMUNICATION LINK

\begin{tabular}{ll}
\hline \hline $\mathrm{Z}_{\text {ANTENNA1 }}=32.02-\mathrm{j} 55.53 \Omega$ & $\mathrm{Z}_{\text {ANTENNA } 5}=57.05-\mathrm{j} 48.68 \Omega$ \\
$\mathrm{Z}_{\text {ANTENNA } 2}=65.38-\mathrm{j} 43.68 \Omega$ & $\mathrm{Z}_{\text {ANTENNA6 }}=38.26+\mathrm{j} 13.31 \Omega$ \\
$\mathrm{Z}_{\text {ANTENNA3 }}=38.76-\mathrm{j} 2.07 \Omega$ & $\mathrm{Z}_{\text {ANTENNA7 }}=56.23+\mathrm{j} 11.41 \Omega$ \\
$\mathrm{Z}_{\text {ANTENNA4 }}=24.32-\mathrm{j} 52.99 \Omega$ & $\mathrm{Z}_{\text {ANTENNA8 }}=43.57+\mathrm{j} 11.45 \Omega$
\end{tabular}

We performed load-pull measurements with the setup shown in Fig. 5. It is composed by an RF microwave source (Keysight ESG4483C), a Maury microwave passive tuner, and a power meter (Keysight N1913A).

First, we characterized the passive tuner in the frequency range of interest by accounting also for the path between the tuner input port and the six-port junction antenna port. Next, we changed the impedance value of the tuner according to a set of impedances as defined in Table II.

The input power at $\mathrm{P} 1$ was $10 \mathrm{dBm}$ and for each load we read the power at P3-P6 and calculated the impedance at the antenna port. We performed the measurements at $5 \mathrm{GHz}, 5.5$. $\mathrm{GHz}$, and $6 \mathrm{GHz}$.

Results are reported in Figs. 6, 7, 8 and in Table III. We obtained a good agreement between the expected antenna values and those derived by the measurements performed with the six-port junction.

In the final sensing board we will replace the power meter with a commercial power detector (LTC5530), which will be also implemented on the same board as the six-port.

TABLE III

IMPEDANCES OBTAINED BY MEASUREMENTS. THE CORRESPONDING EXPECTED VALUES ARE REPORTED IN TABLE II.

\begin{tabular}{|c|c|c|}
\hline $\begin{array}{l}\text { Antenna Load } \\
\text { Measured at } 5 \mathrm{GHz} \\
30.38-\mathrm{j} 56.8 \Omega\end{array}$ & $\begin{array}{l}\text { Antenna Load } \\
\text { Measured at } 5.5 \mathrm{GHz} \\
31.99-\mathrm{j} 53.50 \Omega\end{array}$ & $\begin{array}{l}\text { Antenna Load } \\
\text { Measured at } 6 \mathrm{GHz} \\
28-\mathrm{j} 56.23 \Omega\end{array}$ \\
\hline $69.39-\mathrm{j} 47.71 \Omega$ & $62.72-\mathrm{j} 40.36 \Omega$ & $65.84-\mathrm{j} 50.05 \Omega$ \\
\hline $38.89-\mathrm{j} 3.14 \Omega$ & $36-\mathrm{j} 1.1 \Omega$ & $40.62-\mathrm{j} 2.54 \Omega$ \\
\hline $28.84-\mathrm{j} 55.69 \Omega$ & $20.13-\mathrm{j} 50.8 \Omega$ & $21.01-\mathrm{j} 48.49 \Omega$ \\
\hline $57.46-\mathrm{j} 49.93 \Omega$ & $55-\mathrm{j} 44.6 \Omega$ & $53.63-\mathrm{j} 43.3 \Omega$ \\
\hline $38.25+\mathrm{j} 12 \Omega$ & $39.9+\mathrm{j} 13 \Omega$ & $38.6+\mathrm{j} 8.55 \Omega$ \\
\hline $56.65+\mathrm{j} 8.13 \Omega$ & $53.3+\mathrm{j} 13.52 \Omega$ & $57.38+\mathrm{j} 8 \Omega$ \\
\hline $41.75+j 9.67 \Omega$ & $46.55+\mathrm{j} 10.11 \Omega$ & $45.43+\mathrm{j} 9 \Omega$ \\
\hline
\end{tabular}

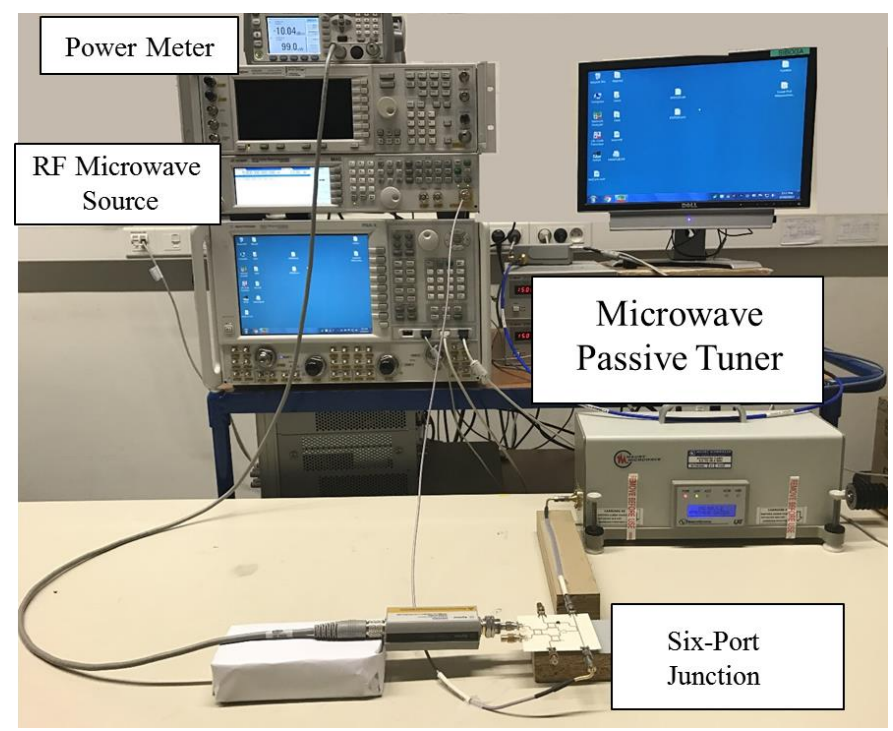

Fig. 5 Measurement setup for load-pull characterization of the realized sixport junction. 


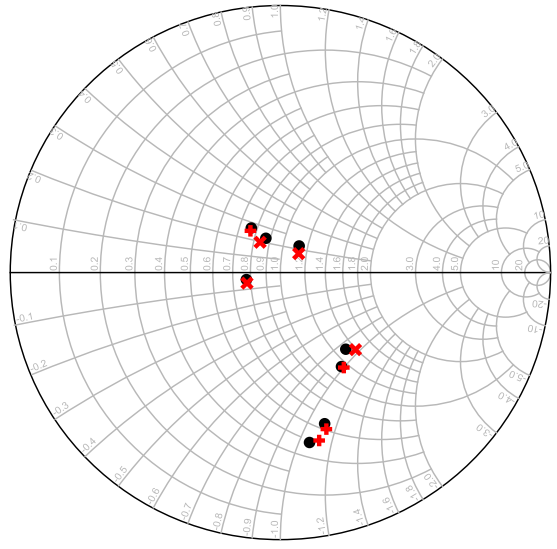

Fig. 6 Measurement results at $5 \mathrm{GHz}$. The black dots are the reference antenna loads (see Table II) and the red crosses are the obtained measured values.

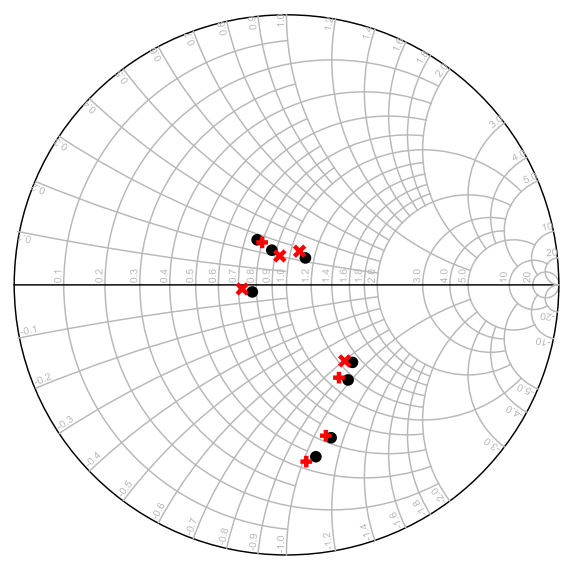

Fig. 7 Measurement results at 5.5 GHz. The black dots are the reference antenna loads (see Table II) and the red crosses are the obtained measured values.

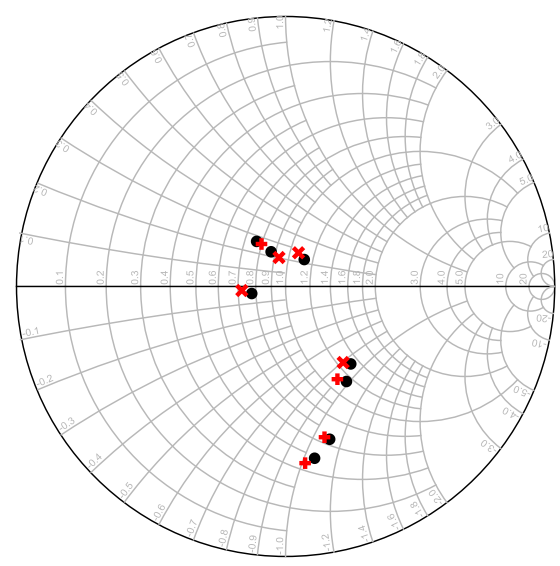

Fig. 8 Measurement results at $6 \mathrm{GHz}$. The black dots are the reference antenna loads (see Table II) and the red crosses are the obtained measured values.

\section{CONCLUSIONS}

We reported an ultra-wideband six-port junction used as a sensing board to detect input impedance variations in RF front-end antenna for IoT and 5G applications. The proposed board was experimentally tested by carrying out load-pull measurements. The results demonstrate that the proposed approach is able to sense properly the antenna's varying input impedance across the specified frequency range.

\section{ACKNOWLEDGMENT}

Authors would like to acknowledge FWO Vlaanderen and Hercules foundation for financial support.

\section{REFERENCES}

[1] D. Bandyopadhyay and J. Sen, "Internet of Things: Applications and Challenges in Technology and Standardization," Wirel. Pers. Commun., vol. 58, no. 1, pp. 49-69, May 2011.

[2] M. Jo, T. Maksymyuk, R. Batista, T. Maciel, A. de Almeida, and M. Klymash, "A Survey of Converging Solutions for Heterogeneous Mobile Networks," IEEE Wirel. Commun., vol. 21, pp. 54-62, December 2014.

[3] D.M. Pozar, Microwave Engineering, Reading, MA: Addison-Wesley, 1990, pp. 529-565.

[4] A.M.M. Mohamed, S. Boumaiza, and R.R. Mansour, "Novel Reconfigurable Fundamental/Harmonic Matching Network for Ehancing the Efficiency of Power Amplifier," Eur. Microw. Conf., Sept. 2010, pp. 1122-1125, France.

[5] D. Ji, J. Jeon, and J.Kim, "A Novel Load Insensitive RF Power Amplifier Using a Load Mismatch Detection and Curing Technique," IEEE RFIC Symposium, pp. 341-344, June 2013.

[6] F. Curticipean and J. Niittylahti, "An Improved Digital Quadrature Frequency Down-Converter Architecture," Conf. on Signals, Systems and Computers, pp. 1318-1321, Nov. 2001.

[7] G. F. Engen, "The Six-Port Reflectometer: An Alternative Network Analyzer," IEEE Trans. Microwave Theory Techn., vol. MTT-25, pp. 1077-1079, Dec. 1977.

[8] F. Engen, "An Improved Circuit for Implementing the Six-Port Technique of Microwave Measurements," IEEE Trans. Microwave Theory Techn., vol. MTT-25, no. 12, pp. 1080-1083, Dec. 1977.

[9] F.M. Ghannouchi and A. Mohammadi, The Six-Port Technique with Microwave and Wireless Application, Artech House, October 2009.

[10] F. M. Ghannouchi and R. G. Bosisio, "An Alternative Explicit Six-Port Matrix Calibration Formalism Using Five Standards, " IEEE Trans. Microwave Theory Techn., vol. 36, no. 3, pp. 494-498, March 1988.

[11] G. Madonna, A. Ferrero, and M. Pirola, "Design of a Broadband Multiprobe Reflectometer", IEEE Trans. Instrum. Meas., vol.48, no. 2, pp.119-121, Apr. 1999.

[12] Lemey, T. Castel, P.Van Torre, T. Vervust, J. Vanfleteren, P. Demeester, D.V. Ginste, and H. Rogier, "Threefold Rotationally Symmetric SIW Antenna Array for Ultra-Short-Range MIMO Communication," IEEE Trans. Antennas Prop., vol. 64, no. 5, pp. 16891699, Feb. 2016. 